\title{
Resolving the Artisan Entrepreneur's Oppositional Identity With Venturing in a Declining City Context
}

\author{
James M. Wilkerson \\ The Pennsylvania State University
}

This article presents conceptual research questions and propositions on the relationship between the artisan entrepreneur's oppositional identity and entrepreneurially venturing in the context of declining cities and urbanized regions. In general, I propose that some features of declining cities typically deemed harmful to business (e.g., deindustrialization, population loss, stifled innovation) may be less problematic for artisan ventures operated with a strong devotion to craft, localness and sense of place, and independence and less emphasis on financial performance than is typical of more mainstream entrepreneurship. The conceptual development herein relies on identity theory (including occupational identity and counter-institutional identity concepts), embeddedness theory, and urban economics concepts. This effort addresses calls for more research on both artisan entrepreneurship and the declining city as a context of entrepreneurship.

Keywords: artisan entrepreneurship, artisan entrepreneurs' oppositional identity, entrepreneurship in declining cities, entrepreneurial context

\section{INTRODUCTION}

Recent research shows growing interest in the various contexts in which entrepreneurship occurs, especially with regard to context effects on new ventures' startups and entrepreneurs' motivations and behaviors (e.g., Davidsson, Recker, \& von Briel, 2020; Dencker, Bacq, Gruber, \& Haas, 2021; Foss, Klein, \& Bjørnskov, 2019; McKelvie, Brattström, \& Dennis, 2021). Expressly incorporating context into entrepreneurship studies enables researchers to know important boundary conditions and exogenous moderating effects on variables and relationships previously researched largely without contextual considerations (Welter, 2011; Zahra, 2007). Artisan entrepreneurship has also attracted recent research interest (Pret \& Cogan, 2019; Ratten, Costa, \& Bogers, 2019; Solomon \& Mathias, 2020), but as is typical with emerging research areas, scholars have only scratched the surface of contextual considerations in artisan entrepreneurship. My purpose in this article is to generate conceptual research questions and propositions as I bring together two subjects, one contextual and one pertaining to artisan entrepreneurship: the artisan entrepreneur's oppositional identity and venturing in the context of declining cities.

Each of these topics is interesting in its own right but all the more so in relation to one another. I aim to integrate the two in a way that may contribute a conceptual starting point for future inquiry of how artisan entrepreneurship, practiced in accord with the artisan's oppositional identity, fares in the context of declining cities. The fundamental question is if there is anything about a declining city that is advantageous to an artisan entrepreneur with a strong oppositional identity. Such a contribution responds to Pret and 
Cogan's (2019) call for more conceptual research on artisan entrepreneurship and how contextual embeddedness, including place effects, influences artisan entrepreneurship. This work also responds to calls for research on how entrepreneurs' perception of their base city's decline may moderate entrepreneurial opportunity recognition and entrepreneurs' risk assessments over time (Wilkerson \& Wafa, 2019).

In cases of typical entrepreneurs and business startups, scholars would certainly expect entrepreneurial identity, as a kind of occupational identity more generally, to influence venturing motivation and behavior (Leitch \& Harrison, 2016; Morris, Neumeyer, Jang, \& Kuratko, 2018; Phelan \& Kinsella, 2009; Pratt, Rockmann, \& Kaufmann, 2006). Artisan entrepreneurs are not usually what we might call typical, "mainstream entrepreneurs" (Hoyte, 2019; Solomon \& Mathias, 2020), however, as one might surmise just from the label of "oppositional identity" being applied to artisan entrepreneurs. Also, unlike in European, Asian, and African research activity, artisan entrepreneurs get relatively little attention in the U.S. academy that produces the dominant discourse in entrepreneurship scholarship (Hill, 2021; Leitch \& Harrison, 2016; Pret \& Cogan, 2019). Another thing that gets scant attention in many studies is the place in which the venture occurs. Entrepreneurship researchers have often neglected place considerations (Anderson, Warren, \& Bensemann, 2019; Korsgaard, Ferguson, \& Gaddefors, 2015; Zahra, 2007), and city-based research samples usually come from small firms in vibrant, growing cities versus cities that seem to have peaked and declined, settling into relatively stagnant and impoverished versions of their former selves (Wilkerson \& Wafa, 2019).

Nonetheless, entrepreneurship does exist in declining cities, as do artisan entrepreneurs specifically. Furthermore, artisan entrepreneurs develop their identities as such through sustained commercial application of their handicraft in environmental context (Kielhofner, 2008), to include in declining cities. Artisan entrepreneurship, influenced by artisans' oppositional identities and associated motivations, does not happen in a vacuum, so if scholars are to understand more fully how artisan entrepreneurship works, then understanding how the declining city's features affect this venturing is a worthwhile pursuit. Ignoring either topic is inappropriate since (a) artisan entrepreneurship is a form of business activity that does contribute to local economies and artisans' well-being and quality of life (Hessels \& Naudé, 2019; Pret \& Cogan, 2019; Ratten et al., 2019; Teixeira \& Ferreira, 2019; Tregear, 2005), and (b) declining cities increasingly matter to national and regional policy makers concerned both with pockets of stubborn economic stagnation and with the widening gap between thriving U.S. cities and declining or stagnating U.S. cities (Holder, 2017). In the following sections, I will briefly review entrepreneurial identity concepts in general and the artisan entrepreneur's oppositional identity in more detail. I will then discuss the placebased venturing context of the declining city with its implications for local business and market conditions as well as social conditions relevant to business. Finally, I will raise research questions and conceptual propositions regarding the likely relationship between the artisan entrepreneur's oppositional identity and venturing in the context of declining cities.

\section{THE ARTISAN ENTREPRENEUR'S OPPOSITIONAL IDENTITY}

\section{What Artisan Entrepreneurs Are and Do}

Artisan entrepreneurs are "individuals who produce and sell products or services which possess a distinct artistic value resulting from a high degree of manual input" (Pret \& Cogan, 2019, p. 594). They are like other entrepreneurs in that they search for or create opportunities to exploit, but unlike other types of entrepreneurs, artisan entrepreneurs' production methods are decidedly manual and traditional in procedures and simple tools used. These handicraft products and services that artisan entrepreneurs make are often culturally, ethnically, traditionally, or locationally inspired (Ratten et al., 2019; SjölanderLindqvist, Skoglund, \& Laven, 2020; Teixeira \& Ferreira, 2019) and typically reflect a custom-made quality and creativity enabled only through skill gained over years of practice and training (Kroezen, Ravasi, Sasaki, Żebrowska, \& Suddaby, in press; Tregear, 2005). Indeed, were the handicrafts not of suitable quality and distinctive appeal, the artisan entrepreneur would not be able to sell them. Some artisan handicrafts include textile and leather garments to wear, rugs to decorate floors, handcrafted leather wallets and purses, specialty soaps for bathing, craft beer to drink or ethnic food to eat, custom-baked goods like 
wedding cakes, custom-made ceramic and metal containers to use in the kitchen or in decorating, handmade jewelry, handmade musical instruments, and handmade wooden furniture and toys (Hill, 2021; Kapp, 2017; Kroezen et al., in press; Ratten et al., 2019; Wolf-Powers et al., 2017). The fact that artisan products and services usually have a practical use to the consumer versus solely an aesthetic appeal is perhaps what distinguishes such handicrafts from fine-art paintings, sculptures, recorded music, dance and theater productions, and so on that consumers also buy chiefly to look at or to listen to.

When artisans begin selling their handicrafts and begin developing a related, identifiable small business, they are engaging in artisan entrepreneurship (Pret \& Cogan, 2019; cf. Glaeser, Rosenthal, \& Strange, 2010) versus remaining, say, hobbyists with no commercial goals (Bouette \& Magee, 2015; WolfPowers et al., 2017). Some artisan entrepreneurs have a strong commercial intent, whereas many others pursue purely lifestyle goals that rank independence and craft fidelity over business growth (Hoyte, 2019; Sjölander-Lindqvist et al., 2020; Tregear, 2005). Many artisan entrepreneurs' businesses remain quite small and informal in survival mode, but some display at least lifestyle mode of operation (more formality and asset accumulation but little long-term growth in employee headcount or sales) or even deliberately managed, ongoing growth in locations, product lines, and employee headcount (Morris et al., 2018). Many artisan entrepreneurs' businesses are part-time endeavors, at least until they can generate enough income for the artisan to leave other employment and work full-time in their own firms (Hill, 2021; Wolf-Powers et al., 2017). Some artisan entrepreneurs are driven into self-employment of necessity after losing a job, whereas for others this venturing onset is a planned, deliberate choice not conditioned on dire necessity but instead on higher-order needs met by intrinsic satisfaction from plying their craft (Dencker et al., 2021; Hessels, van Gelderen, \& Thurik, 2008).

\section{Artisan Entrepreneurs' Identities}

Artisan entrepreneurs who start and lead their own firms develop occupational identities that reflect their dedication to their handicraft and accordingly shape their entrepreneurial behaviors. This comports with identity theory. Identity theory holds that identity is essentially a schematic self-characterization, or meaningful designation, that tells people about themselves as unique persons, role performers, and social group members (Anderson et al., 2019; Carter, 2013). Regarding the latter especially, one's social identity signals both similarity to and differences from other people in various situations and groupings. Identity is activated when the meanings about self that are conveyed by the identity match the meanings perceived in a role demand or social situation. Internally and psychologically held yet socially constructed, identity answers more than one's questions of "Who am I and what am I about both generally and in this present situation?" Identity is also a strong guide to people's motivations, goals, and behaviors (Carter, 2013; Leitch \& Harrison, 2016), as anyone observing the stunning insurrectionist behavior at the U.S. Capitol building on January 6, 2021, could surmise.

Much less dramatic than the insurrectionist's identity is the artisan entrepreneur's identity that also reflects the influence of social construction on goals, motivations, and behaviors. This social construction is formed by handicraft training and work experiences as well as craft-related ideals that customers and other artisans validate, manifesting itself in venturing behaviors and choices strongly consistent with and expressive of artisan identity (Leitch \& Harrison, 2016). Thus, we understand artisan entrepreneur identity as a specific and powerful kind of occupational identity that is similar to what Pratt et al. (2006) observed about professionals' identities in that employed artisans and artisan entrepreneurs derive meaning much more from what they do than from organizational membership. Hands-on craft labor and efforts to sell resulting handicrafts to appreciative customers both serve to shape artisan entrepreneurs' identities in early years (i.e., identity formation that is both self-performative and socially constructed; Anderson et al., 2019) and are continually governed by those identities in later years (Kielhofner, 2008; Leitch \& Harrison, 2016; Phelan \& Kinsella, 2009). This identification process relies on both the artisan entrepreneur's personal agency (choices made and volition exercised in sustained craft work and commercial efforts) and dynamic sociocultural context that gives meaning to and generates demand for the handicrafts.

Solomon and Mathias (2020) explored connections between artisan entrepreneurs' identities and their small firms' growth prospects, drawing in part on recent research in counter-institutional identities (Chreim, 
Langley, Reay, Comeau-Vallée, \& Huq, 2020). Chreim et al. explained that counter-institutional organizational forms (such as many artisanal ventures) arise when the members of the emerging organizations view the dominant institution as somehow unacceptable or inappropriate. This viewpoint stems from a counter-institutional identity that enduringly rejects the dominant institution's prescriptions, business models, values, principles, role definitions, training and socialization precepts, and practices. Applying Chreim et al.'s work to the institution of entrepreneurship suggests that artisan entrepreneurs with a counter-institutional identity may elaborate this identity in part by defining themselves specifically as who they are not and what they are not about in their venturing. They may also gravitate toward membership in artisan guilds and clubs (Kroezen et al., in press) for "echo chamber"-style social validation and reinforcement of their counter-institutional identity, simultaneously clarifying "who we are" while more sharply distinguishing themselves from "who we are not."

Similarly, Luckman (2018) noted how unconventional artisan entrepreneurs can be, describing it partly in terms of an oppositional view of what entrepreneurial success is. Standard entrepreneurship defines success chiefly in terms of accumulating wealth, typically by growing the small business (Hessels \& Naudé, 2019). Artisan entrepreneurs Luckman studied regarded success less in financial terms, however, and more in terms of satisfaction with their beloved handicraft work, deliberate smallness of operation, and valuedriven lifestyle considerations. Tregear (2005) wrote of this in terms of artisan entrepreneurs being either "lifestyle-seeking" or "commercially minded" (p. 4) and finding the former prevalent. Artisan entrepreneurs Tregear studied rejected standard entrepreneurial emphases on profitability, growth, and eventually joining retail store chains, embracing instead independence, devotion to local community, and small firm size.

Solomon and Mathias's (2020) definition of artisan entrepreneurs reflects counter-institutional identity, noting that artisan entrepreneurs emphasize manual production, independence, local community, and intrinsic value creation over the mass production, conglomeration, expansive scaling, and profit maximization, respectively, that entrepreneurs typically emphasize when pursuing aggressive growth, equity capital, or a big payday when their surging venture gets acquired by a huge competitor. Solomon and Mathias (2020) found evidence that artisan entrepreneurs' counter-institutional identities are essentially two-sided (a relational side and an oppositional side), with the artisan entrepreneur's preference for independence influencing which identity aspect has most influence on venture decisions and actions. The artisan entrepreneur's relational identity was associated with the artisan firm's growth and accommodating stakeholders, whereas the oppositional identity did not support firm growth, reflecting instead devotion to maintaining traditional artisanal standards and to keeping the business small enough to remain independent.

This oppositional identity reflects significant ways artisan entrepreneurs and their firms are not like mainstream entrepreneurial ventures, consistent with Chreim et al. (2020). Artisan entrepreneurs with strong oppositional identities may abhor other firms' mass production enabled by automation, constant growth efforts (including growing away geographically from their local roots), willingness to merge with other firms or to be acquired, pursuit of standardized quality and efficiencies, and so forth. Artisan entrepreneurs seeking to reflect and to be true to their oppositional identities may instead be quick to declare their fidelity with traditional, manual craft methods that, while not particularly efficient or high-volume, deliver authentic, custom quality (Kapp, 2017; Kroezen et al., in press). These artisan entrepreneurs may also proudly highlight how they prioritize craft ahead of profit and wealth and how their ventures' strictly local existence and small size reflect their independence and associated freedom not to become like "those other firms" that conform to the dominant entrepreneurial institution of practice (Solomon \& Mathias, 2020; cf. Hessels et al., 2008).

This comports with other researchers' observations of how artisan entrepreneurs are often uninterested in the kind of entrepreneurship so often glorified in Western culture, mainly in laudatory accounts of tiny businesses started from scratch that grew into booming success stories or were so successful as to be snatched up by giant competitors, always with heroic founding entrepreneurs becoming fabulously wealthy (Luckman, 2018; Tregear, 2005). This also comports with predictable reactions to identity distinctiveness threat (Kershaw, Rast, Hogg, \& van Knippenberg, 2021). That is, artisan entrepreneurs know they are part of the larger, general population of entrepreneurs and small-business owners, but their strong identity as artisan entrepreneurs serves as a distinction they prefer and rely on for sensemaking. Thus, lumping them 
together with other kinds of entrepreneurs without due recognition of their artisan nature represents an identity distinctiveness threat that is bound to spur their claims of oppositional identity-related contrasts (Kershaw et al., 2021).

\section{THE DECLINING CITY AS CONTEXT}

Entrepreneurship's context, or relevant (in terms of being enabling or constraining) setting outside entrepreneurs and their firms, is multidimensional, and one contextual dimension is the geospatial location where the venture exists (Shrivastava \& Kennelly, 2013; Welter, 2011). Artisan entrepreneurs venture in a variety of locations and places, including in and immediately around cities. Although much research featuring entrepreneurship in regions and nations has focused on large, reasonably healthy cities (Salder \& Bryson, 2019), urban locations take a variety of forms, ranging from small cities to massive cities, cities with densely packed infrastructures and populations to sprawling cities, cities in naturally beautiful locations to cities in locations of bleak natural topography, cities with centuries of history to fairly young cities of just a few decades old, and cities with vibrant economies and population growth to cities in decline.

In keeping with Wilkerson and Wafa (2019), I do not focus herein on cities in emerging economies and regions enjoying a generally upward trajectory, nor on purely tiny-town, rural settings where low levels of entrepreneurship, economic activity, urbanization, and population have always existed. A past history of a markedly more robust, significant profile from which the city has declined is meaningful because that history and its structural, cultural, and institutional vestiges are relevant to contemporary entrepreneurship in that declining city. My interest is in such declining cities, which Wilkerson and Wafa (2019) described as "slowly declining from past statures of higher prominence, bigger population, larger industry base, growing wages, and other features that made for vibrant local conditions" and as cities that "once had a heyday, a more promising and vibrant past profile than what they have now" (p. 130; see also "urban shrinkage" in Ročak, Hospers, \& Reverda, 2016). In the U.S., some "rust belt" cities stand out as postindustrial, declining cities, including some whose populations have shrunk by more than 50 percent from their decades-past peaks, including Buffalo, New York; Niagara Falls, New York; Pittsburgh, Pennsylvania; Gary, Indiana; Cleveland, Ohio; Youngstown, Ohio; Detroit, Michigan; and St. Louis, Missouri (Jacobs, 2018).

Declining cities are similar to what Johnstone and Lionais (2004) termed "depleted communities" which stagnate in a region displaying persistent economic decline even as other regions thrive (cf. Gherhes, Vorley, \& Williams, 2018). The depleted community declines in terms of both its space (i.e., economic downturn and resource depletion) and its place (i.e., social problems, including slowly shrinking population, that attend economic downturn and deindustrialization). Conventional, for-profit entrepreneurship is not a strong feature of the depleted community's past, so some of the social, material, and institutional elements required for successful (at least as defined in conventional terms) entrepreneurial venturing are missing (Gherhes et al., 2018). The declining cities Wilkerson and Wafa (2019) described are perhaps larger than the depleted communities Johnstone and Lionais studied, but the decline dynamics are essentially the same. Also common to both is strong place attachment among much of the resident population, to include some small-business owners (McKeever, Jack, \& Anderson, 2015). Accordingly, the location's population loss is slow as the oldest residents die, the declining city no longer draws a net surplus of people moving to it, the majority of residents stay despite mounting problems due to the city's decline, and some of the younger residents move away (Ročak et al., 2016).

\section{Embeddedness in the Declining City}

Artisan entrepreneurs venturing in and immediately around a declining city find themselves in an urban context with stagnant or slowly shrinking population, deindustrialization, job losses, low wage growth and rising poverty, and suppressed innovation (Wilkerson \& Wafa, 2019). In a sense, the context is one in which agglomeration and urbanization's usual benefits (large local markets, accessible generic and specialized resources, innovation and knowledge spillover effects, etc.; Amezcua, Ratinho, Plummer, \& Jayamohan, 2020; Bosma \& Sternberg, 2014; Glaeser et al., 2010) are fading from a prior level of greater munificence. 
This would not necessarily matter save for the fact that artisan entrepreneurs are embedded, for better or for worse, in this context (Korsgaard et al., 2015; McKeever et al., 2015). Embeddedness theory suggests that the artisan entrepreneurs develop ties to the declining city and these ties may either help or hurt the artisanal venture (Jack \& Anderson, 2002; McKeever et al., 2015). Furthermore, it is not just the city's physical location and associated space to which the artisan entrepreneur is linked; the declining city's history, traditions, and culture also define the place, and thus affect the embedded artisan entrepreneur (Anderson et al., 2019; Hoyte, 2019; Korsgaard et al., 2015: Shrivastava \& Kennelly, 2013; SjölanderLindqvist et al., 2020).

In Jack and Anderson's (2002) view of embeddedness, embedding makes the entrepreneur part of the local social structure and extends beyond merely social networking into the local structural context itself. Entrepreneurs are more embedded when their ties to the declining city are more complex, deeper, and more extensive. This does not imply that more embeddedness always equates to more entrepreneurial success (e.g., more opportunity identification and resource access), for (a) the structural context in which the entrepreneur is embedded may be fraught with threats and restrictions, and (b) the entrepreneur's venturing activities can conflict with social, physical, economic, and institutional processes, features, norms, and entities to which the entrepreneur is tied. Embeddedness also does not imply a one-way relationship in which the declining city's context affects the entrepreneur; instead, the embedded entrepreneur's venture both affects and is affected by the local context (a reciprocal structuration dynamic; Jack \& Anderson, 2002; Pret \& Cogan, 2019; Salder \& Bryson, 2019).

Korsgaard et al. (2015) pointed out that most entrepreneurship research that relies on embeddedness theory focuses much more on social networks and institutional environment than on local spatial context, which includes the elements I mentioned above (i.e., the location's material infrastructure, topography, and meanings instilled in the location by local tradition and culture). Beyond the purely social, Korsgaard et al. held that a material location such as a declining city "becomes a place if meanings and experiences are attached to it" (p. 579; cf. Guthey, Whiteman, \& Elmes, 2014; Johnstone \& Lionais, 2004; Shrivastava \& Kennelly, 2013). As to networks, the declining city's social networking potential may be reduced due to the characteristic "brain drain" and population loss destabilizing networks as talented people leave for better prospects in more promising locations (Gherhes et al., 2018; McKeever et al., 2015).

Other scholars have also spoken to entrepreneurial embeddedness in local place (e.g., Salder \& Bryson, 2019), but far fewer scholars have researched entrepreneurs' (and especially artisan entrepreneurs') activity in declining city contexts. Anderson et al. (2019) addressed entrepreneurial identity enactment in a declining place but focused on a small-town, rural setting rather than an urban setting. Nonetheless, the small town studied was depleted, largely post-industrial, and in decline before some modest revitalization due to an identity-enacting entrepreneur vigorously engaging with the local setting. Anderson et al. found that place - in its full meaning and form of material, physical location plus situated culture plus local social effects plus local socioeconomic history-informed the focal entrepreneur's identity and growth-focused venturing activity. The entrepreneurial activity in declining cities is often not strong and aimed at growing small businesses, however, as highly localized, subsistence-mode entrepreneurship prevails (Gherhes et al., 2018). Often in declining cities, an entrepreneur's decision to establish a local physical location and hire local employees is largely driven by sunk-cost considerations of the founder's local residence and lifestyle choices, local family ties, and so forth, all of which strengthen the venture's local embeddedness (Salder \& Bryson, 2019).

Some research has focused on artisan entrepreneurs and also considered place effects. Because of how handicrafts often reflect a particular culture, and because culture is experienced in place and informs the meaning of place, artisanal ventures may be more locally tied than other kinds of entrepreneurial ventures (Shrivastava \& Kennelly, 2013; Teixeira \& Ferreira, 2019). Like Teixeira and Ferreira, Ratten et al. (2019) studied artisan entrepreneurship in a regional tourism context and observed both that handicrafts' cultural associations can be with local communities and that artisan entrepreneurship sometimes revitalizes cities. In some cases, artisan entrepreneurs repurpose abandoned buildings, spaces, and material in declining cities. This activity both supports local material infrastructure's sustainability (Guthey et al., 2014) and can support the social-relations dimension of entrepreneurship as artisans jointly occupy and interact (with one 
another and the local community) in repurposed space such as so-called makerspaces (Hill, 2021; Kapp, 2017; Ratten et al., 2019; Wolf-Powers et al., 2017). Once artisan entrepreneurs establish their physical working space in the city, they are often resistant to the idea of relocating, especially if staying put means their employees do not have to commute far and they do not somehow dilute their firms' images by moving to some industrial park or office park outside the city (Tregear, 2005).

\section{QUESTIONS, CONNECTIONS, AND PROPOSITIONS}

Given the above discussion, what is the likely relationship between the artisan entrepreneur's oppositional identity and venturing in the context of declining cities? We know that artisan entrepreneurs with oppositional identities are not like most other entrepreneurs, for such artisan entrepreneurs reject business growth and, necessarily, much of the profit-driven wealth that comes with having a strongly growing business. They instead focus on and valorize being true to their craft's standards and related ideals of authenticity, traditional design and production methods, and the like (Kroezen et al., in press; SjölanderLindqvist et al., 2020; Solomon \& Mathias, 2020). This devotion to hands-on design and making, as well as strong attachment to local place and strong preference for remaining small in business scale, has been observed among artisan entrepreneurs even in studies that did not invoke the oppositional identity construct at all, ones focusing instead on, for instance, urban economic development (e.g., Wolf-Powers et al., 2017). Is there anything about the context of a declining city that matters to this oppositional identity one way or the other? Does maintaining the oppositional identity in a declining city likely lead to more business success (however defined) or more difficulties? As asked above, is there anything about a declining city that is advantageous to an artisan entrepreneur with a strong oppositional identity?

Solomon and Mathias (2020) identified four oppositional identity attributes that many artisan entrepreneurs display and that inspire their strong devotion to identity-consistent choices, behaviors, and business activities. Considering these four elements of this oppositional identity, which of them is likely affected by the declining city context, and how? The first element of the artisan entrepreneur's oppositional identity is "craft as opposed to low-quality mass production" (Solomon \& Mathias, 2020, 10th page of electronic publication). Craft often implies not only technical production and manually instilled quality features, but also cultural features and traditions that relate to the locality (Hoyte, 2019; Pret \& Cogan, 2019; Sjölander-Lindqvist et al., 2020; Teixeira \& Ferreira, 2019). Artisan entrepreneurship opportunity may exist in a declining city because the long-term portion of the city's population with multigenerational ties to the place displays a stubborn devotion to social and cultural norms, values, and customs of the location, even long after the old ways and views have become decidedly unsuited to present economic realities (Gherhes et al., 2018; Wilkerson \& Wafa, 2019). In such a context, the artisan entrepreneur's work is viewed not as an awkward anachronism but as a laudable nod to fondly remembered tradition.

Proposition 1a: Hysteresis in the declining city's informal institutions is associated with the artisan entrepreneur's strong devotion to craft.

Whether or not artisan entrepreneurship relates strongly to innovation, as the general field of entrepreneurship often treats the concept, is questionable. Certainly, artisans can be innovative in a creative sense as they hone their handicraft (Hoyte, 2019; Sjölander-Lindqvist et al., 2020), but artisan entrepreneurs with oppositional identities are not especially interested in the kinds of technological and business-model innovation so often associated with scaling up or automating operations, starting new businesses based on high technology, and the like. Thus, artisan entrepreneurs with oppositional identities may feel somewhat more comfortable in declining cities where innovation is generally suppressed and, accordingly, less likely to threaten the traditional, even old-fashioned nature of their handicrafts.

Proposition 1b: The declining city's relatively suppressed level of innovation in technology application and business models is associated with the artisan entrepreneur's strong devotion to craft. 
The stagnant or declining state of industrialization and commercial development in the declining city may make more acceptable the hyper-focus on craft of artisan entrepreneurs with oppositional identities. It is not that all industry vanishes in the declining city. Also, it is not that all positive agglomeration externalities, especially the ones attending urbanization in the form of generic resources (infrastructure, commercial banks and business services, serviceable office space, local government support services, etc.), are gone in the declining city (Amezcua et al., 2020). They are, however, fewer than in the city's past and potentially less well-funded as a function of deindustrialization and resident population loss. Demand for those generic resources fades, producing a secondary loss of jobs to accompany the job losses from deindustrialization. Put simply, when the declining city has been shedding industries and jobs in recent decades, some business activity, even quaint handicraft production in a small artisan firm, and even only a few newly created artisan jobs are better than none at all. Growing cities with active urbanization are potentially less welcoming to artisan firms and perhaps less respectful of what craft means, preferring instead the more admired kind of entrepreneurship that pursues significant growth in jobs and operational scale.

Proposition 1c: Deindustrialization in the declining city is associated with the artisan entrepreneur's strong devotion to craft.

The second element of the artisan entrepreneur's oppositional identity is "independence as opposed to conglomerate-owned" (Solomon \& Mathias, 2020, 10th page of electronic publication). More than anything else, this identity feature is associated with the artisan firm's smallness (McKelvie et al., 2021). Even artisan entrepreneurs engaged in craft enterprises that eventually develop regional product distribution (e.g., some craft brewers) tend to resist selling out to huge category players and competitors, preferring instead to remain independent and privately owned, free to continue using traditional handicraft methods, however inefficient by Wall Street standards (Kroezen et al., in press; Sjölander-Lindqvist et al., 2020). Certainly, the declining city's mayor, Chamber of Commerce, and others with a stake in economic development would welcome the potential growth in jobs that could come with a local firm being acquired by a very large corporation. The same urban economic realities discussed above apply to this independence issue, however, as well as many declining cities' diminishing localization (concentration of same-industry firms; Amezcua et al., 2020). The artisan entrepreneur with an oppositional identity thus finds staying small and independent an easier endeavor in the declining city, both because large firms intent on acquiring the small, artisan business are simply not coming to the declining city and local competitors in the same artisan field may not even exist, offering no pressure to grow or unwelcome opportunity to merge.

Proposition 2: Deindustrialization in the declining city is associated with the artisan entrepreneur's strong devotion to independence.

The third element of the artisan entrepreneur's oppositional identity is "community/localism as opposed to large ubiquitous corporations" (Solomon \& Mathias, 2020, 10th page of electronic publication). This relates somewhat to staying independent and operationally small, but the main point here is that the artisan entrepreneur's oppositional identity favors one location, not many, and that one establishment is here in this local place, which the identity also favors. This identity attribute also translates to a preference for localized supply chains. Lifestyle considerations (Tregear, 2005), attachment-rich "sense of place" versus mere awareness of space (Guthey et al., 2014; Shrivastava \& Kennelly, 2013, p. 84), and especially embeddedness in the community (Ratten et al., 2019; Salder \& Bryson, 2019; Sjölander-Lindqvist et al., 2020) matter to the artisan entrepreneur's devotion to localness as an expression of oppositional identity.

Tregear (2005) held that stagnating consumer demand, such as we would expect in a declining city context given slowly shrinking resident population, puts the artisan entrepreneur's growth goals and lifestyle goals in opposition. In such cases, lifestyle considerations such as socioemotional effects of local embeddedness, sense of place, sunk costs of residency and business establishment location, and so forth win out, making the local place the place to be (Salder \& Bryson, 2019; Shrivastava \& Kennelly, 2013). 
The declining city's vacant retail stores, abandoned industrial buildings, and stagnant residential housing market also permit the artisan entrepreneur's oppositional identity expression regarding localness. Housing is often relatively cheap in the declining city, which suits the artisan entrepreneur's personal budget, and empty commercial space also is relatively cheaper to rent or to buy (Kapp, 2017; Wilkerson \& Wafa, 2019). Setting up house in the local area certainly increases the artisan entrepreneur's local ties. Setting up shop in local space only embeds the artisan firm all the more in the local community, especially as ensuing relationships develop with local customers, other artisan firms, and suppliers (Hill, 2021; Kapp, 2017; Shrivastava \& Kennelly, 2013).

Proposition 3: Embeddedness and accessible business space in the declining city are associated with the artisan entrepreneur's strong devotion to localness.

The fourth element of the artisan entrepreneur's oppositional identity is "non-financial focus as opposed to seeking profit maximization" (Solomon \& Mathias, 2020, 10th page of electronic publication). With artisan entrepreneurs, plying craft comes first and building their firms comes second at best (Hoyte, 2019), even if that means their employees have but modest or low wages and their firms do not resemble mainstream entrepreneurship ventures (Solomon \& Mathias, 2020). Earning comfortable livings that sustain their families' lifestyles is typically more important to artisan entrepreneurs with oppositional identities than is becoming personally wealthy (Sjölander-Lindqvist et al., 2020). Amassing great wealth is not a primary goal for the artisan entrepreneur with an oppositional identity, which may be a good thing relative to effects of the declining city's slow population decline (shrinking local customer base), relatively low wage growth (fewer dollars to spend on handicrafts), and job losses with related higher poverty rates. True, authentic handicraft products, especially ones custom-made locally, have enjoyed increased demand among certain consumer segments, some with very wealthy consumers, in recent years (Kroezen et al., in press; Ratten et al., 2019; Solomon \& Mathias, 2020; Wolf-Powers et al., 2017). Such consumers may even live in and around a declining city, but the declining city's economic realities offset much of this effect, keeping artisan businesses' income modest at best.

Artisan entrepreneurs are not impervious to the limitations declining cities pose for business, of course, and they cannot stay in business without profit. The artisan entrepreneurs with oppositional identities, however, just do not care so much if that translates into only modest financial performance. They gauge their success in more ways than financial, not the least of which is their fidelity to their craft. As "artisan entrepreneurs," they emphasize the "artisan" first and foremost, and many barely embrace the "entrepreneur" part (Luckman, 2018).

Proposition 4: The declining city's shrinking population, rising poverty, below-average wages, and aboveaverage unemployment are associated with the artisan entrepreneur's strong devotion to a non-financial focus.

\section{FUTURE RESEARCH AND POLICY IMPLICATIONS}

Identity theory, embeddedness theory, and urban economics concepts all conceptually support that the artisan entrepreneur's oppositional identity, enacted in the context of a declining city, matters to artisan entrepreneurship. Future empirical research should proceed from this conceptual basis to test my propositions. If future research finds empirical evidence supporting the foregoing conceptual propositions and answering questions I have raised, the field will have made an important contribution in relating effects of the declining city's venturing context to artisan entrepreneurship generally and artisan entrepreneurs' oppositional identities specifically. Future research could also delve more deeply and answer questions in which the present variables are tested in comparison to others. For instance, I could see the value of testing relevant outcome variables (firm growth, firm survival, entrepreneur well-being, product diversification, opportunity identification, and so on) against a $2 \times 2$ positioning of artisan entrepreneurship and "mainstream/other" entrepreneurship crossed with declining city context and thriving city context. Another 
area of future research could be applying the literature that views artisan entrepreneurship as a feature of tourism promotion (e.g., Ratten et al., 2019; Teixeira \& Ferreira, 2019) to the context of declining cities. Not all declining cities are located in regions lacking tourism appeal. Exploring the nexus of declining cities, tourism, and artisan entrepreneurship would be useful, especially in its implications for the city's revitalization.

Future research must also investigate how well internet-based platforms permit artisan entrepreneurs to remain relatively true to their oppositional identities while still overcoming the relatively bleak financial realities of venturing in a declining city. Again, artisan entrepreneurs cannot stay in business without profit, so internet commerce may be a way for them to achieve at least the revenues needed for survival. Online resources such as the Etsy.com platform enable artisan entrepreneurs to ply their beloved handicrafts in their local, embedded manner; have no need to relocate, thanks to the nearest local post office or parcel delivery service's drop-box creating a simple, outbound supply chain link to distant customers; remain independent of acquisition or pressure to sell equity ownership if they so desire; and pursue as few or as many internet sales as their financial aspirations compel (Wolf-Powers et al., 2017). Indeed, Etsy's 2019 Integrated Annual Report and website text extol "unique handcrafted pieces;" identify "handmade goods" as Etsy's first-cited category of permitted items to sell; acknowledge entrepreneurial users' small-business profile; and describe the Etsy mission as "to keep human connection at the heart of commerce" (or, in its shortened version, "keep commerce human"), thus sending a clear signal appealing to artisan entrepreneurs' identity-based devotion to handicraft and independence (Etsy, 2020).

This is akin to what Korsgaard et al. (2015) observed in the cases of rural entrepreneurs who enjoyed the benefits of place embeddedness while also selectively relying on non-local, specialized networks for certain resources their local environment lacked. The declining city's relative lack of some resources may be less an issue for the artisan entrepreneur who augments purely local commerce with internet-enabled commerce. Future research should investigate this more, taking care to note if, in fact, such activity remains truly consistent with the artisan entrepreneur's oppositional identity versus presenting identity distinctiveness threats with associated problematic effects (Kershaw et al., 2021).

Whether or not artisan entrepreneurship gets due consideration in discussions about revitalizing stubbornly stagnant, post-industrial American cities remains to be seen. The declining city's officials and interested stakeholders so often seem to long for yesteryear's profile that featured robust, big-industry presence in and around the city, bigger population, urban development, and other positives, and they want heroic, aggressive-growth types of entrepreneurial ventures (Morris et al., 2018) to bring back those glory days. Of course, they do not typically regard artisan entrepreneurship as the answer because artisan firms typically stay small and modest in financial performance, largely as a function of artisan entrepreneurs' oppositional identities. These artisan entrepreneurs' relatively low status is ironic to the extent these same entrepreneurs perpetuate local traditions and capture local historical meanings uniquely relevant to the city in some of their handicrafts and adaptive reuse of industrial spaces first built in a bygone era. Furthermore, the regionally distinctive, cultural element in artisan entrepreneurs' work and output can add to the declining city's appeal as a place to live and possibly to work, thus addressing some of the population decline issue that declining cities face (Anderson et al., 2019; Kapp, 2017; Pret \& Cogan, 2019; WolfPowers et al., 2017).

Granted, public resources are always limited, but policy makers may find that artisan entrepreneurship's demand on public resources is relatively much lighter than that of entrepreneurs pursuing aggressive venture growth. This may be welcome news when considering that entrepreneurship levels in cities depend in part on availability of material inputs and financing (Glaeser et al., 2010). To the extent some artisan entrepreneurs repurpose and salvage abandoned buildings and material things (Kapp, 2017), a declining city may well offer more than adequate supplies of certain material inputs. To the extent artisan entrepreneurs' oppositional identities make them less likely to need advanced machinery, their financing needs may well be relatively modest compared to mainstream entrepreneurs' needs, which is also in the declining city's favor. Supporting artisan entrepreneurs may be more feasible for declining cities with tighter budgets and relatively suppressed sponsorship of entrepreneurship. 
Perhaps the good news is artisan entrepreneurs are generally loath to leave their location, even if a declining one. The bad news is those same artisan entrepreneurs have relatively little interest in scaling up their small firms or pursuing efficiencies, much to the chagrin of local stakeholders wanting to see employment growth, local supply chain expansion, and so forth (Hessels et al., 2008; Wolf-Powers et al., 2017). Korsgaard et al. (2015) suggest the answer is not to push artisan entrepreneurs to scale up and to grow in ways their oppositional identities preclude but instead to achieve economic development through enabling more and different artisanal ventures. This would require declining cities' policy makers, economic-development officials, and other local stakeholders both to recognize diversity among entrepreneurs and to abandon either-or thinking when considering supporting "mainstream" entrepreneurship versus artisan entrepreneurship. This, in turn, would comport with development economics research that has noted how variety in entrepreneurship (not solely startups in high-technology sectors or high-growth mode of operating) can signal to policy makers what the declining city is and is not particularly good at producing (Hessels \& Naudé, 2019). In any case, policy makers in declining cities are likely disserved by clinging to a narrow view of what entrepreneurship should be like, for as Bobadilla, Goransson, and Pichault (2019) put it, "the life and death issue for the future of older industrial cities is to find new ways of development" (p. 378).

Entrepreneurial diversity affects the foregoing policy considerations, so we should also note that even artisan entrepreneurs cannot be considered a homogeneous group. Personality, ethnic, and gender differences among artisan entrepreneurs predictably influence their venturing behaviors, and identity-based differences in venturing goals exist (Hoyte, 2019; Pret \& Cogan, 2019; Tregear, 2005). Also, the elements of the artisan entrepreneur's oppositional identity may not all be equally ascendant at any given time. Solomon and Mathias (2020) raised the possibility that, depending on the demands of the particular handicraft category, the artisan entrepreneur's oppositional identities' attributes could differ in relative importance. I suggest that embeddedness matters to this, too. For instance, nostalgic sentiments in declining cities may translate to whatever demand exists for artisan handicrafts tapping the localness and craft attributes of the artisan entrepreneur's oppositional identity more than the independence and non-financial attributes. In any case, future research on how artisan entrepreneurs' oppositional identities shape venturing in declining cities must account for differences even within the local artisan entrepreneur community.

A final area of inquiry needing attention implicates another kind of diversity: diversity in national cultures. The context I have focused on herein is the declining city, replete with agglomeration, urbanization, deindustrialization, and localization effects (Amezcua et al., 2020). Such urban economic effects can occur in any city worldwide, but my point of reference has admittedly been that of the American rust belt city. It is in the U.S. as much as or more than anywhere else that artisan entrepreneurship with its oppositional identity effects may encounter its foil in the form of what I have repeatedly described as the growth-focused, "mainstream" kind of entrepreneurship (Solomon \& Mathias, 2020) so often valorized in U.S. culture. Researchers should not ignore the nexus of the declining-city context and the national culture's context (in a sense, localized embeddedness versus broader, national embeddedness) when exploring interaction with the artisan entrepreneur's oppositional identity. For instance, might the declining city's effects on artisan entrepreneurship be different in Asian or Scandinavian declining cities than they are in U.S. declining cities as a function of national culture and associated values as well as institutional differences (McKelvie et al., 2021)? Are artisan entrepreneurs' oppositional identities less challenged in non-U.S. declining cities? Only comparative studies can answer questions like these, and these studies should involve collaborations between well-informed scholars from each of the focal nations so that national culture considerations are accurately integrated when exploring how artisan entrepreneurs' oppositional identities affect their business venturing outcomes in declining cities across the globe. 


\section{REFERENCES}

Amezcua, A., Ratinho, T., Plummer, L.A., \& Jayamohan, P. (2020). Organizational sponsorship and the economies of place: How regional urbanization and localization shape incubator outcomes. Journal of Business Venturing, 35, 105967. doi: 10.1016/j.jbusvent.2019.105967

Anderson, A.R., Warren, L., \& Bensemann, J. (2019). Identity, enactment, and entrepreneurship engagement in a declining place. Journal of Small Business Management, 57(4), 1559-1577. doi: $10.1111 /$ jsbm. 12406

Bobadilla, N., Goransson, M., \& Pichault, F. (2019). Urban entrepreneurship through art-based interventions: Unveiling a translation process. Entrepreneurship \& Regional Development, 31 (56), 378-399. doi: 10.1080/08985626.2018.1539125

Bosma, N., \& Sternberg, R. (2014). Entrepreneurship as an urban event? Empirical evidence from European cities. Regional Studies, 48(6), 1016-1033. doi: 10.1080/00343404.2014.904041

Bouette, M., \& Magee, F. (2015). Hobbyists, artisans and entrepreneurs: Investigating business support and identifying entrepreneurial profiles in the Irish craft sector. Journal of Small Business and Enterprise Development, 22(2), 337-351. doi: 10.1108/JSBED-02-2013-0022

Carter, M.J. (2013). Advancing identity theory: Examining the relationship between activated identities and behavior in different social contexts. Social Psychology Quarterly, 76(3), 203-223. doi: $10.1177 / 0190272513493095$

Chreim, S., Langley, A., Reay, T., Comeau-Vallée, M., \& Huq, J. (2020). Constructing and sustaining counter-institutional identities. Academy of Management Journal, 63(3), 935-964. doi: 10.5465/amj.2017.0528

Davidsson, P., Recker, J., \& von Briel, F. (2020). External enablement of new venture creation: A framework. Academy of Management Perspectives, 34(3), 311-332. doi: 10.5465/amp.2017.0163

Dencker, J.C., Bacq, S., Gruber, M., \& Haas, M. (2021). Reconceptualizing necessity entrepreneurship: A contextualized framework of entrepreneurial processes under the condition of basic needs. Academy of Management Review, 46(1), 60-79. doi: 10.5465/amr.2017.0471

Etsy, Inc. (2020). 2019 integrated annual report. Retrieved from https://investors.etsy.com/home/default.aspx

Foss, N.J., Klein, P.G., \& Bjørnskov, C. (2019). The context of entrepreneurial judgment: Organizations, markets, and institutions. Journal of Management Studies, 56, 1197-1213. doi: 10.1111 joms. 12428

Gherhes, C., Vorley, T., \& Williams, N. (2018). Entrepreneurship and local economic resilience: The impact of institutional hysteresis in peripheral places. Small Business Economics, 51, 577-590. doi: 10.1007/s11187-017-9946-7

Glaeser, E.L., Rosenthal, S.S., \& Strange, W.C. (2010). Urban economics and entrepreneurship. Journal of Urban Economics, 67, 1-14. doi: 10.1016/j.jue.2009.10.005

Guthey, G.T., Whiteman, G., \& Elmes, M. (2014). Place and sense of place: Implications for organizational studies of sustainability. Journal of Management Inquiry, 23(3), 254-265. doi: $10.1177 / 1056492613517511$

Hessels, J., \& Naudé, W. (2019). The intersection of the fields of entrepreneurship and development economics: A review towards a new view. Journal of Economic Surveys, 33(2), 389-403. doi: $10.1111 /$ joes. 12286

Hessels, J., van Gelderen, M., \& Thurik, R. (2008). Entrepreneurial aspirations, motivations, and their drivers. Small Business Economics, 31, 323-339. doi: 10.1007/s11187-008-9134-x

Hill, I.R. (2021). Spotlight on UK artisan entrepreneurs' situated collaborations: Through the lens of entrepreneurial capitals and their conversion. International Journal of Entrepreneurial Behavior \& Research, 27(1), 99-121. doi: 10.1108/IJEBR-11-2019-0642

Holder, S. (2017, September 26). America's most and least distressed cities. Bloomberg. Retrieved from https:/www.bloomberg.com/news/articles/2017-09-26/america-s-most-distressed-and-mostprosperous-cities 
Hoyte, C. (2019). Artisan entrepreneurship: A question of personality structure? International Journal of Entrepreneurial Behavior \& Research, 25(4), 615-632. doi: 10.1108/IJEBR-02-2018-0099

Jack, S.L., \& Anderson, A.R. (2002). The effects of embeddedness on the entrepreneurial process. Journal of Business Venturing, 17, 467-487.

Jacobs, S. (2018, January 14). 10 American cities that have fallen into decline. Business Insider. Retrieved from https://www.businessinsider.com/us-census-data-population-decrease-showsamerican-cities-in-decline-2018-1

Johnstone, H., \& Lionais, D. (2004). Depleted communities and community business entrepreneurship: Revaluing space through place. Entrepreneurship \& Regional Development, 16, 217-233. doi: $10.1080 / 0898562042000197117$

Kapp, P.H. (2017). The artisan economy and post-industrial regeneration in the US. Journal of Urban Design, 22(4), 477-493. doi: 10.1080/13574809.2016.1167588

Kershaw, C., Rast, D.E., Hogg, M.A., \& van Knippenberg, D. (2021). Divided groups need leadership: A study of the effectiveness of collective identity, dual identity, and intergroup relational identity rhetoric. Journal of Applied Social Psychology, 51, 53-62. doi: 10.1111/jasp.12715

Kielhofner, G. (2008). Dimensions of doing. In G. Kielhofner (Ed.), Model of human occupation: Theory and application (4th ed., pp. 101-109). Baltimore, MD: Lippincott Williams \& Wilkins.

Korsgaard, S., Ferguson, R., \& Gaddefors, J. (2015). The best of both worlds: How rural entrepreneurs use placial embeddedness and strategic networks to create opportunities. Entrepreneurship \& Regional Development, 27(9-10), 574-598. doi: 10.1080/08985626.2015.1085100

Kroezen, J., Ravasi, D., Sasaki, I., Żebrowska, M., \& Suddaby, R. (2021). Configurations of craft: Alternative models for organizing work. Academy of Management Annals, 15(2), 502-536. doi: 10.5465/annals.2019.0145

Leitch, C.M., \& Harrison, R.T. (2016). Identity, identity formation and identity work in entrepreneurship: Conceptual developments and empirical applications. Entrepreneurship \& Regional Development, 28(3-4), 177-190. doi: 10.1080/08985626.2016.1155740

Luckman, S. (2018). Craft entrepreneurialism and sustainable scale: Resistance to and disavowal of the creative industries as champions of capitalist growth. Cultural Trends, 27(5), 313-326. doi: 10.1080/09548963.2018.1534574

McKeever, E., Jack, S., \& Anderson, A. (2015). Embedded entrepreneurship in the creative reconstruction of place. Journal of Business Venturing, 30, 50-65. doi: 10.1016/j.jbusvent.2014.07.002

McKelvie, A., Brattström, A., \& Dennis, W.J., Jr. (2021). What do they think and feel about growth? Examining small business managers' attitudes towards growth in the United States. Journal of Business Venturing Insights, 15, e00243. doi: 10.1016/j.jbvi.2021.e00243

Morris, M.H., Neumeyer, X., Jang, Y., \& Kuratko, D.F. (2018). Distinguishing types of entrepreneurial ventures: An identity-based perspective. Journal of Small Business Management, 56(3), 453-474. doi: $10.1111 /$ jsbm. 12272

Phelan, S., \& Kinsella, E.A. (2009). Occupational identity: Engaging socio-cultural perspectives. Journal of Occupational Science, 16(2), 85-91. doi: 10.1080/14427591.2009.9686647

Pratt, M.G., Rockmann, K.W., \& Kaufmann, J.B. (2006). Constructing professional identity: The role of work and identity learning cycles in the customization of identity among medical residents. Academy of Management Journal, 49(2), 235-262. doi: 10.5465/amj.2006.20786060

Pret, T., \& Cogan, A. (2019). Artisan entrepreneurship: A systematic literature review and research agenda. International Journal of Entrepreneurial Behavior \& Research, 25(4), 592-614. doi: 10.1108/IJEBR-03-2018-0178

Ratten, V., Costa, C., \& Bogers, M. (2019). Artisan, cultural and tourism entrepreneurship. International Journal of Entrepreneurial Behavior \& Research, 25(4), 582-591. doi: 10.1108/IJEBR-05-20180319

Ročak, M., Hospers, G., \& Reverda, N. (2016). Searching for social sustainability: The case of the shrinking city of Heerlen, The Netherlands. Sustainability, 8, 382. doi: 10.3390/su8040382 
Salder, J., \& Bryson, J.R. (2019). Placing entrepreneurship and firming small town economies: Manufacturing firms, adaptive embeddedness, survival and linked enterprise structures. Entrepreneurship \& Regional Development, 31(9-10), 806-825. doi: $10.1080 / 08985626.2019 .1600238$

Shrivastava, P., \& Kennelly, J.J. (2013). Sustainability and place-based enterprise. Organization \& Environment, 26(1), 83-101. doi: 10.1177/1086026612475068

Sjölander-Lindqvist, A., Skoglund, W., \& Laven, D. (2020). Craft beer-building social terroir through connecting people, place and business. Journal of Place Management and Development, 13(2), 149-162. doi: 10.1108/JPMD-01-2019-0001

Solomon, S.J., \& Mathias, B.D. (2020). The artisans' dilemma: Artisan entrepreneurship and the challenge of firm growth. Journal of Business Venturing, 35(5), 106044. doi: 10.1016/j.jbusvent.2020.106044

Teixeira, S.J., \& Ferreira, J.J.M. (2019). Entrepreneurial artisan products as regional tourism competitiveness. International Journal of Entrepreneurial Behavior \& Research, 25(4), 652-673. doi: 10.1108/IJEBR-01-2018-0023

Tregear, A. (2005). Lifestyle, growth, or community involvement? The balance of goals of UK artisan food producers. Entrepreneurship \& Regional Development, 17(1), 1-15. doi: $10.1080 / 08985620420002497777$

Welter, F. (2011). Contextualizing entrepreneurship - Conceptual challenges and ways forward. Entrepreneurship Theory and Practice, 35(1), 165-184. doi: 10.1111/j.1540-6520.2010.00427.x

Wilkerson, J.M., \& Wafa, M.A. (2019). Entrepreneurial opportunity recognition in a declining city: Shrewd choice or wishful thinking? Journal of Applied Business and Economics, 21(2), 129-140. doi: $10.33423 /$ jabe.v21i1.1460

Wolf-Powers, L., Doussard, M., Schrock, G., Heying, C., Eisenburger, M., \& Marotta, S. (2017). The maker movement and urban economic development. Journal of the American Planning Association, 83(4), 365-376. doi: 10.1080/01944363.2017.1360787

Zahra, S.A. (2007). Contextualizing theory building in entrepreneurship research. Journal of Business Venturing, 22, 443-452. doi: 10.1016/j.jbusvent.2006.04.007 